\title{
Achieving Universal Wearing of Face Masks During the COVID-19 Pandemic: A Practical Solution from Shanghai, China
}

This article was published in the following Dove Press journal: Risk Management and Healthcare Policy

\author{
Tiantian Zhang ${ }^{1, *}$ \\ Qian Wang $\mathbb{B}^{1, *}$ \\ Wenming Shi ${ }^{1}$ \\ Tao Sheng ${ }^{2}$ \\ Jiaxing Liu (iD ${ }^{3}$ \\ Jiejin Zhao ${ }^{4}$ \\ Yuanmin Huang $\mathbb{D}^{3}$ \\ Yutian Xia $\mathbb{1 D}^{3}$ \\ Zhanyi Liu ${ }^{5}$ \\ Ruiming Dai ${ }^{1}$ \\ Zhenyu Bao ${ }^{2}$ \\ Ping $\mathrm{Wu}^{\prime}$ \\ Site $\mathrm{Xu}{ }^{\prime}$ \\ Li Luo ${ }^{1,6}$
}

'School of Public Health, Fudan University, Shanghai 200032, People's Republic of China; ${ }^{2}$ School of Computer Science and Technology, Fudan University, Shanghai 201203, People's Republic of China; ${ }^{3}$ School of Software, Fudan University, Shanghai 20I203, People's Republic of China; ${ }^{4}$ Shanghai Municipal Commission of Commerce, Shanghai 200125, People's Republic of China; ${ }^{5}$ Shanghai Civil Affairs Bureau, Shanghai 200125, People's Republic of China; ${ }^{6}$ Key Laboratory of Public Health Safety of the Ministry of Education and Key Laboratory of Health Technology Assessment of the Ministry of Health, Fudan University, Shanghai 200032, People's Republic of China

*These authors contributed equally to this work

Correspondence: Li Luo Fudan University, I30 Dong'an Road, Xuhui District, Shanghai, People's

Republic of China

Email liluo@fudan.edu.cn
Background: Face masks are basic protective equipment for preventing respiratory infectious diseases. The measures to properly dispose of and allocate face masks during the early stage of an epidemic caused by respiratory infectious diseases deserve worldwide attention. Methods: A qualitative research approach was used to document the practice of a citywide face mask-wearing strategy of the Shanghai Municipal Government (called the "Shanghai solution" in this article). Based on data from government work documents, an online face mask-allocation and sales system was built to offer real-time updates of face-mask appointments and sales information in all designated pharmacies and neighborhood committees in Shanghai.

Results: In the Shanghai solution, a total of 24.8 million residents in 6,031 committees were covered, in order to achieve universal wearing of face masks during the COVID-19 crisis. Up to 110 million face masks were dispensed to residents in six rounds of face-mask allocation during February to April. This practical experience in Shanghai solved two key problems (insufficient face-mask capacity, protection of vulnerable population) with the supply of face masks by addressing four essential characteristics: overall coordination, on-demand distribution, efficient distribution, and technical support.

Conclusion: The practice of the citywide face mask-supply strategy of Shanghai could provide several pointers for management of a shortage of emergency materials, dispatch, and transport to other countries during the pandemic.

Keywords: face mask, COVID-19, public health emergency, respiratory infections, China

\section{Introduction}

In recent years, infectious diseases have been emerging worldwide with high frequency. ${ }^{1-3}$ For unknown infectious diseases, it is difficult to detect the pathogens and transmission patterns in time. Therefore, in the early stages of an epidemic, nonpharmaceutical intervention, such as using personal respiratory protective equipment, is particularly important in decreasing respiratory infection risk when vaccination or specific anti-infection treatments are unavailable. ${ }^{4}$

In December 2019, COVID-19 broke out in China and then continued to spread all over the world. Epidemiological investigations found some cases had been caused by asymptomatic individuals. Early detection and prevention became difficult, because asymptomatic carriers were difficult to detect. Therefore, the Shanghai Municipal Government required all citizens to wear face masks in public places to mitigate transmission of the disease. ${ }^{5}$ 
There are two major difficulties in this work. Firstly, the production capacity of face masks is insufficient to meet the needs of all citizens. At the beginning of the COVID-19 pandemic, the daily production capacity of face masks in Shanghai was about 1.5-1.8 million, whereas local citizens needed about 20 million face masks per day. Secondly, it is difficult for vulnerable groups, such as the elderly, the poor, and those who lack social resources, to acquire face masks at a reasonable price. Influenced by the COVID-19 pandemic, the world is facing a long-term shortage of personal protective equipment, such as masks and gloves. On February 7, the WHO reported that the demand for personal protective equipment was 100 times the norm and the price 20 times that of normal. ${ }^{6}$ The vulnerable populations mentioned have difficulty acquiring face masks. ${ }^{7,8}$ Under this situation, how to ensure the supply of face masks and make them available for all are the most urgent challenges for the government to deal with.

In this study, we aimed to document a citywide face mask-supply strategy of the Shanghai Municipal Government during the COVID-19 pandemic, which may provide some suggestions to other countries about how better to manage the preparation, dispatch, and transportof emergency materials in shortage.

\section{Methods}

\section{Work Records}

Data for the "Shanghai solution" were collected through field investigations, policy reports, and government documents.

\section{Data-Management Platform}

We obtained daily face mask-allocation and sales data from a job-specific online platform for six manufacturing companies, 58 logistics and distribution companies, 6,031 neighborhood committees, 1,182 pharmacies, 24.8 million residents, and about 120 million face masks sold. This platform was freely accessible to certain users (commerce committee, pharmacies, neighborhood committees, and research team) from February to April (http://spmd. haiyul.com/analysis). However, the data platform was closed after April 30, due to the termination of facemask allocation and sales in Shanghai, since the COVID19 epidemic at that time was controlled.

\section{Ethics}

This study was exempted from the need for ethics approval after a discussion with the Ethical Committee of the School of Public Health, Fudan University, because the study protocol had neither an intervention nor a breach of privacy or anonymity. All data used in this study were deidentified.

\section{Data Analysis}

We collected information on Shanghai solution through work records and insider interviews, which supplied details of the plan's operation and how to improve its operability. Based on real-time data from the platform, we used time-series statistical charts and distribution maps to show the implementation process and effects of the Shanghai solution. The mathematical model showed an example of how to calculate the face-mask quota that a community can obtain on a particular day on the platform.

$$
Q c=P_{t} * \frac{\Sigma A c * 5-S p c}{\Sigma A t * 5-\Sigma S p t} * 100 \%
$$

where Qc is the quota of face masks available to a community on a particular day, $\mathrm{P}_{\mathrm{t}}$ predicted number of face masks available to the city on that day, $\Sigma A c * 5$ number of face masks needing to be allocated to a community at the end of the day, Ac on a specific day, the number of people in a community to whom face masks need to be distributed, At on a specific day, the number of people in the whole city to whom face masks need to be distributed. Each $\Sigma$ sign here represents the cumulative number of people added over all days before the date of quota calculation. Multiplying by five serves to translate the number of people into the number of face masks, since every person was able to purchase five face masks at most in a single round of allocation. Spc is the number of face masks that can be allocated to the community from the cumulative inventories of the pharmacy designated to the community, $\Sigma$ Spt the sum of cumulative inventories of all designated pharmacies around the city. If $\Sigma A c * 5-S p c<0, \quad$ then $\quad S p c=\Sigma A c * 5 . \quad$ If $Q c>\Sigma A c * 5-S p c$, then $Q c=\Sigma A c * 5-S p c$.

Suppose that the value of Qc is calculated on day $i$, in theory it should indicate the distribution pattern for the day after, which is $i+1$. However, since logistic distribution and subpackaging of face masks should take about a day, that Qc value has to be used to guide the distribution for day $i+2$ in reality. As a result, the number of face masks distributed to this community on day $\mathrm{i}+1$ should be taken into consideration and estimated. It was usually estimated according to the sales data in the past few days. 
Therefore, the calculation of $\Sigma A c$ could be written with more details:

$$
\Sigma A c=\Sigma A_{i}-\Sigma A_{i+1}
$$

where $\Sigma A c$ is the number of face masks needing to be allocated to meet the unsatisfied reservations in a community, calculated on day $\mathrm{i}$ and to be issued on day $i+2 \Sigma A_{i}$ the cumulative number of unsatisfied facemask reservations in a community on day $i, \Sigma A_{i+1}$ the estimated number of face masks distributed to this community on day $\mathrm{i}+1$.

$$
\begin{aligned}
& S p c=\operatorname{Spc}_{\mathrm{i}}-\min \left(\mathrm{Spc}_{\mathrm{i}+1}\right) \mathrm{Spc} \\
& =\frac{\sum \mathrm{A}_{\mathrm{c}}}{\sum \mathrm{A}_{\mathrm{p}}} *\left(\mathrm{Spt}_{\mathrm{i}}-\min \left(\mathrm{Spt}_{\mathrm{i}+1}\right)\right)
\end{aligned}
$$

where $\mathrm{Spc}$ is the number of face masks that can be allocated to the community among the cumulative inventories of the pharmacy designated to the community, Aptthe number of people to whom face masks need to be distributed from a single pharmacy on a specific day. This pharmacy could provide face masks to multiple communities. $\Sigma A p t$ is the cumulative number of people to whom face masks need to be distributed from this pharmacy over all the past days, calculated on day $\mathrm{i}, \mathrm{s}, \mathrm{Spc}_{\mathrm{i}} \mathrm{Spt}_{\mathrm{i}}$. Cumulative inventories of this pharmacy on the calculation day $\mathrm{i}, \min \left(\mathrm{Spc}_{i+1}\right): \min \left(\mathrm{Spt}_{\mathrm{i}+1}\right)$. Minimum cumulative inventories of this pharmacy on the day after calculation date $i$.

\section{Results}

\section{Overview of the Shanghai Solution}

An overview of the Shanghai solution for obtaining and distributing face masks to citizens during the COVID-19 pandemic is clearly depicted in Figure 1. The core process of the framework includes the following steps. 1) Set the basic units of face-mask demand-and-supply organization, including neighborhood committees and designated pharmacies. 2) The residents report their demand information to neighborhood committees, forming the personal demand-information database. 3) The neighborhood committees review all the personal demand information and form the demand information of the whole neighborhood. 4) Match the geographical location of the neighborhood and the designated pharmacies, and obtain the supply information of the designated pharmacies according to the demand information of their corresponding neighborhood. 5) The designated pharmacies summarize the demand information and calculate the total number of demands. 6) Calculate the daily supply capacity according to the production capacity of the enterprise, emergencypurchase quantity, and inventory. 7) Calculate the allocation cycle according to the total number of face masks demanded and the daily supply capacity. For example, if the total demand is 20 million, the daily supply is 2 million, and the emergency-allocation cycle will need 10 days. 8) Calculate the daily supply capacity of designated pharmacies through the total number of demands and the allocation cycle. 9) Frame a logistics plan according to the logistic relationship among production enterprises, distribution enterprises, and designated pharmacies. 10) Dynamically adjust the logistics plan every day according to changes in total demand, daily supply, and daily inventory information of face masks in designated pharmacies. 11) The neighborhood committees tell the residents to purchase masks at the designated pharmacies according to queueing information after the face masks have been delivered to the designated drugstore. 12) The sales information and inventory information of face masks are enetered into the information system every night.

\section{Solution to Problem I: Insufficient Production Capacity \\ Face Mask-Allocation Rule}

Face mask-allocation work in Shanghai adopted the method of reservation in community and purchase in the designated pharmacies. Each citizen in Shanghai could go to the designated locations of neighborhood committee to make an on-site registration or register online with valid personal identification. After verifying the personal identification and family information, the neighborhood committee would send a reservation voucher to the resident's mailbox containing such information as the unique reservation number and address of the designated pharmacy. To purchase the face masks, residents could visit the prescribed pharmacy on the voucher within a specified period after receiving the telephone notice from the neighborhood committee. In order to avoid queueing and crowds, the neighborhood committee assigned their staff to maintain order and make sure that everyone maintained appropriate social distancing (at least $1 \mathrm{~m}$; Table 1).

\section{Family-Quota Rule}

Shanghai stipulated that each household could purchase no more than five face masks through reservation in each round of face-mask allocation. As of writing, the reservation and sales work in Shanghai had been conducted for five rounds. Those households that had made a reservation in the last round 


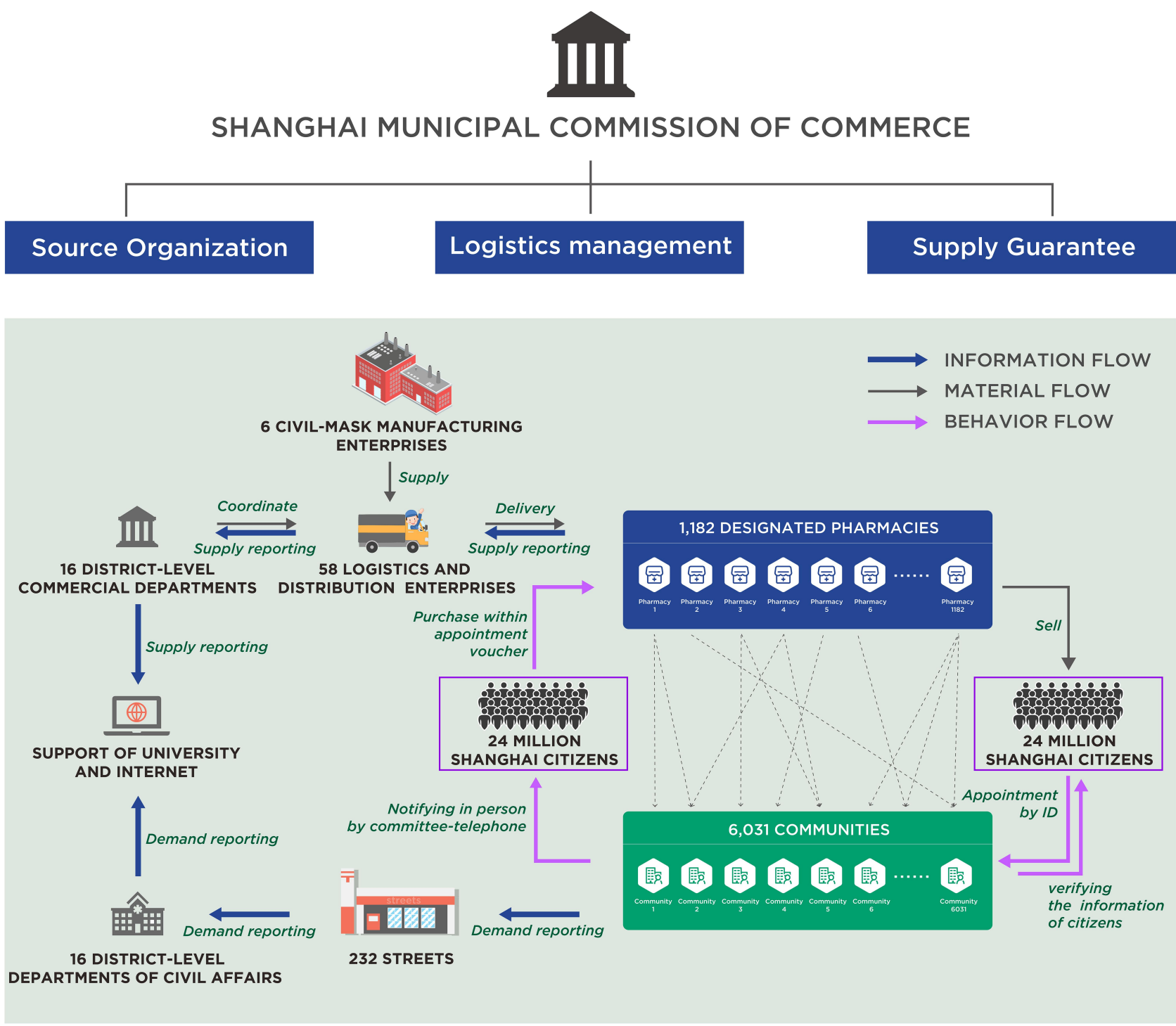

Demand Integration
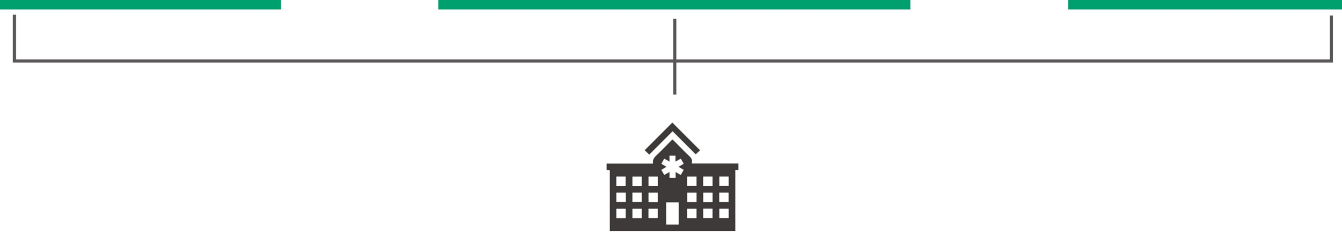

\section{SHANGHAI CIVIL AFFAIRS BUREAU}

Figure I Overview of the Shanghai solution for obtaining and distributing face masks to residents during the COVID-19 pandemic.

of allocation but had failed to purchase face masks would be given priority to purchase first in the next round.

Solution to Problem 2: Difficulty in Ensuring That All Vulnerable Persons Receive Face Masks with Priority In order to ensure the accessibility of face masks for vulnerable populations, there are three difficulties that need to be tackled: accurately locate and identify the vulnerable populations, establish a queueing mechanism and ensure the priority of vulnerable populations, and ensure the affordability of face masks. The practical solutions in Shanghai for how to deal with these three difficulties were as follows, which could give some references. 
Table I Specific Rules and Ideas of the Shanghai solution

\begin{tabular}{|l|l|l|}
\hline & Objective & Rules \\
\hline Insufficient production capacity & $\begin{array}{l}\text { Help every citizen in need get a face mask within } \\
\text { a certain period }\end{array}$ & Face mask-allocation rule \\
\cline { 2 - 3 } & Family-quota rule \\
\hline $\begin{array}{l}\text { Difficulty in ensuring that all vulnerable } \\
\text { people can receive face masks with } \\
\text { priority }\end{array}$ & $\begin{array}{l}\text { Accurately locate and identify vulnerable } \\
\text { populations }\end{array}$ & $\begin{array}{l}\text { Neighborhood committees collect information } \\
\text { on vulnerable populations }\end{array}$ \\
\cline { 2 - 3 } & $\begin{array}{l}\text { Establish queueing mechanisms and ensure the } \\
\text { priority of vulnerable populations }\end{array}$ & $\begin{array}{l}\text { Increasing the waiting time for nonvulnerable } \\
\text { populations to get face masks by establishing } \\
\text { a queueing mechanism }\end{array}$ \\
\cline { 2 - 3 } & Ensure the affordability of face masks & Keeping the price of each face mask below US $\$ 0.28$ \\
\hline
\end{tabular}

Neighborhood Committees Collect Information on Vulnerable Populations

Neighborhood committees collected information on vulnerable populations through a survey or inquiry of each family, accurately locating and identifying elderly, disabled, and poor populations as the priorities for accessing face masks. Then, locations and personal information for these vulnerable populations would be recorded in the registration-information system. As such, the information system obtains the key information of all the vulnerable populations, including the detailed demand for face masks and geographical information.

Increase Waiting Time for Nonvulnerable Populations to Get Face Masks by Establishing a Queueing Mechanism According to the characteristics of vulnerable populations, the platform established data sets through data cleaning and feature engineering, and modeled and trained convolutional neural networks. The system then classified people by machine learning and established a queuing mechanism through classification results. According to the daily supply of face masks, vulnerable populations with the highest priority are selected from the queue for priority distribution. Other nonvulnerable populations should purchase face masks through the process of making a reservation in the community, receiving phone notification, and purchasing in the designated pharmacy, which increase the waiting time for obtaining face masks. In this way, those people who already have enough face masks would decrease their purchases and the possibility of vulnerable people to receive face masks would be increased.

Purchase at a Fair Price, But Not Free, to Avoid Wastage and Ensure Affordability

In order to avoid material wastage and ensure affordability for vulnerable populations, Shanghai sold face masks at an affordable price instead of allocating them free. Due to differences in brands, costs, and processes of production, the price of face masks varied slightly, with a range of US $\$ 0.06-0.28$ per piece.

\section{Four Key Characteristics of the Shanghai Solution}

The following four characteristics of the Shanghai solution make it applicable for precise allocation of emergency materials during any epidemic (Table 2).

\section{Overall Coordination}

The working team of the distribution of civilian face masks was headed by the Shanghai Municipal Commission of Commerce and the Shanghai Civil Affairs Bureau, under the leadership of the mayor of the Shanghai Municipal Government in charge of this sector, together with other municipal departments concerned. During the COVID-19 pandemic, the team requisitioned all six face mask-manufacturing enterprises in Shanghai to ensure production of the face masks. These six enterprises supplied about 1.5-2 million civilian masks per day, together with another 58 requisitioned distribution enterprises scheduling and taking the lead in coordinating between municipal and district-level commercial departments. The 16 district-level commercial departments were responsible for guiding and arranging the sales work of 1,182 designated pharmacies within the jurisdiction, and were also in charge of urging them promptly to report daily purchases, sales, and inventory information on a specialized online information platform. The Shanghai Civil Affairs Bureau took responsibility for ensuring timely communication between 6,031 neighborhood committees (in 232 streets) and citizens, and took the lead in 
Table 2 Four Key Characteristics and Essential Functions of the Shanghai Solution

\begin{tabular}{|c|c|c|}
\hline & Specific meaning & Essential functions \\
\hline $\begin{array}{l}\text { Overall } \\
\text { coordination }\end{array}$ & $\begin{array}{l}\text { Supported by the Shanghai Municipal Commission of Commerce and the } \\
\text { Shanghai Civil Affairs Bureau, the team for scientific distribution of } \\
\text { civilian face masks covered I } 6 \text { administrative districts, } 58 \text { distribution } \\
\text { companies, I, I } 82 \text { designated pharmacies, } 232 \text { streets, and } 6,03 \text { I } \\
\text { neighborhood committees in Shanghai. }\end{array}$ & $\begin{array}{l}\text { To improve the efficiency of official protective material } \\
\text { allocation }\end{array}$ \\
\hline $\begin{array}{l}\text { On-demand } \\
\text { distribution }\end{array}$ & $\begin{array}{l}\text { This involved establishment of a many (neighborhoods)-to-one } \\
\text { (designated pharmacy) distribution channel for civilian face-mask } \\
\text { purchase. Daily logistics and quota plans were issued based on citizen } \\
\text { demand. }\end{array}$ & $\begin{array}{l}\text { To ensure that all organizations coordinated smoothly } \\
\text { and protective materials distributed in an orderly } \\
\text { manner }\end{array}$ \\
\hline $\begin{array}{l}\text { Efficient } \\
\text { distribution }\end{array}$ & $\begin{array}{l}\text { Logistics companies were equipped with specialized manpower and } \\
\text { material resources for face-mask distribution under government funding } \\
\text { and supervision. The government also established an open complaint- } \\
\text { reporting hotline system for public supervision on face-mask allocation } \\
\text { and sales work. }\end{array}$ & $\begin{array}{l}\text { To ensure the safe and timely delivery of protective } \\
\text { materials }\end{array}$ \\
\hline $\begin{array}{l}\text { Technical } \\
\text { support }\end{array}$ & $\begin{array}{l}\text { This process visualized real-time and dynamic collection of citizen } \\
\text { appointments and pharmacy sales and realized daily automatic } \\
\text { generation of logistical solutions. }\end{array}$ & $\begin{array}{l}\text { To obtain clear and transparent data and innovate } \\
\text { government coordination and supervision approaches }\end{array}$ \\
\hline
\end{tabular}

coordinating the work among the municipal and districtlevel civil affairs departments. The 16 district-level civil affairs departments were responsible for arranging the neighborhood committees to issue reservation vouchers to residents in need and for coordinating the relationship between the neighborhood committees and the designated retail pharmacies.

\section{On-Demand Distribution}

This process involved establishment of a distribution channel of many neighborhoods to one designated pharmacy for civilian face-mask purchase among 24 million citizens, 6,031 neighborhoods, 232 streets, 1,182 designated pharmacies, and 58 distribution enterprises. Only Shanghai Healthcare Insurance-assigned pharmacies were selected. Assigned pharmacies in Shanghai have a high reputation, because of the advantages of 10-minute arrival for any citizen, 24-hour operation, and superior facilities. ${ }^{9}$ Altogether, 1,182 pharmacies were identified and chosen carefully from nearly 4,000 pharmacies in the city, and a connection network between neighborhoods and designated pharmacies was constructed. The quota of face masks for each neighborhood and each designated pharmacy was adjusted dynamically and accurately every day based on residents' daily face-mask demand collected by the 6,031 neighborhoods and daily purchases, sales, and inventory information from the 1,182 designated pharmacies. Subsequently, a daily logistics plan was formulated for the 58 distribution companies. A scientific and precise control strategy was implemented every day.

\section{Efficient Distribution}

A total of 58 pharmaceutical logistics and distribution enterprises were mobilized to establish an efficient face mask-distribution system in Shanghai during the COVID19 pandemic. These enterprises were required to be equipped with special human and material resources for distribution of civilian face masks under government funding and supervision. The government established an open complaint-reporting hotline for public supervision of facemask allocation and sales work.

\section{Technical Support}

The Shanghai solution explored establishing a supportive working information platform (http://spmd.haiyul.com/analy sis). The platform was constructed with the following functions (see Figures 2 and 3): visual, real-time, and dynamic monitoring of each pharmacy's quota, purchases, sales, stocks, and inventory, collection of daily reservation data for each community, and daily automatic generation of logistical solutions. The working group would then make decisions about the production quantity, specifications, and price of face masks based on the data from the platform accordingly. Details on calculation methods for the daily logistical plan are clearly shown in the Methods section. 


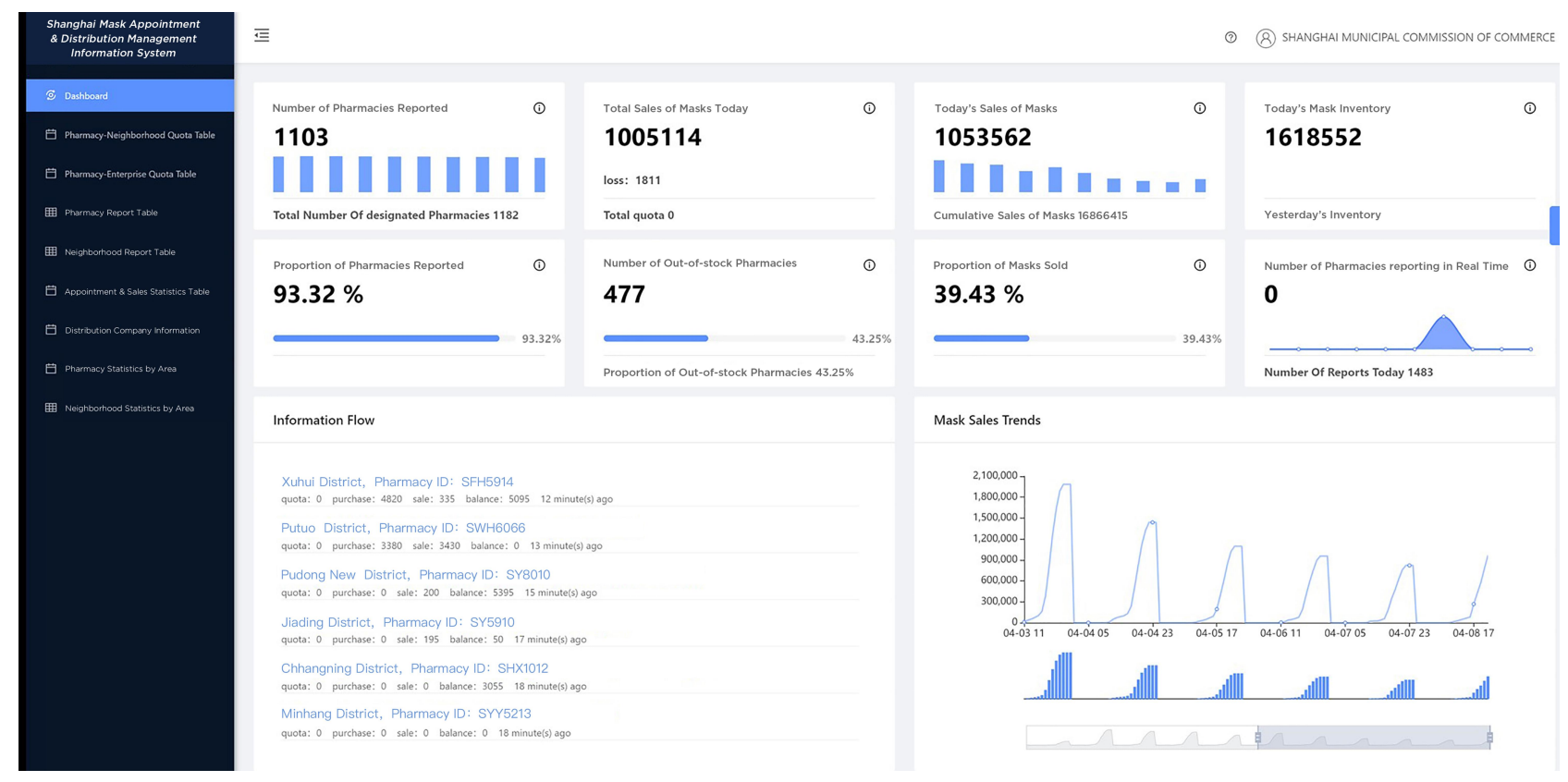

Figure 2 System home page (part of the dashboard) used by the government during the COVID-19 epidemic in Shanghai.

\begin{tabular}{|c|c|c|c|c|c|c|c|c|}
\hline City/Region & Number of Designated Pharmacy & $\begin{array}{l}\text { Number of pharmacies } \\
\text { Reported }\end{array}$ & $\begin{array}{l}\text { Total uootat of Reported } \\
\text { Pharmacies }\end{array}$ & $\begin{array}{l}4 \text { Total Purcchase of Repoorted } \\
\text { Pharmacies }\end{array}$ & Yesterday's Inventory & loss & $\begin{array}{l}\text { Total Sales of Reported } \\
\text { Pharmacies }\end{array}$ & Current Inventory \\
\hline Shanghai & 1182 & $584(49.4 \%)$ & 700855 & 139460 & 2244470 & 1962 & $360570(32.2 \%)$ & 759505 \\
\hline \multicolumn{9}{|c|}{ Real-time Regional Statistics } \\
\hline City/Region & Number of Designated Pharmacy & $\begin{array}{l}\text { Number of pharmacies } \\
\text { Reported }\end{array}$ & $\begin{array}{l}\text { Total Ooutat o f Reeported } \\
\text { Pharmacies }\end{array}$ & $\begin{array}{l}\text { Total Purchase of Reported } \\
\text { Pharmacies }\end{array}$ & Yesterday's Inventory & loss & $\begin{array}{l}\text { Total S Sales of Reported } \\
\text { Pharmacies }\end{array}$ & \\
\hline Chongming District & 45 & $45(100.0 \%)$ & 11680 & 350 & 6316 & 10 & $3400(51.1 \%)$ & 3256 \\
\hline Jinshan District & 46 & $38(82.6 \%)$ & 7345 & 0 & 6833 & 0 & $380(13.9 \%)$ & 2350 \\
\hline Qingpu District & 42 & $32(76.2 \%)$ & 7700 & 370 & 6965 & 0 & $465(17.5 \%)$ & 2185 \\
\hline Baoshan District & 92 & $55(59.8 \%)$ & 80455 & 18830 & 211571 & 0 & 49490 (39.6\%) & 75377 \\
\hline Jing' an District & 52 & $28(53.8 \%)$ & 52840 & 28970 & 125204 & 2 & 27235 (32.7\%) & 56014 \\
\hline Pudong New District & 251 & $127(51.6 \%)$ & 262760 & 39130 & 788927 & 58 & $110473(25.2 \%)$ & 327767 \\
\hline Yangpu District & 45 & $23(51.1 \%)$ & 79465 & 8700 & 215668 & 1820 & 57035 (38.5\%) & 91080 \\
\hline Songjiang District & 106 & $53(50.0 \%)$ & 21305 & 4720 & 53740 & 0 & 14965 (48.2\%) & 16094 \\
\hline Jiading District & 78 & $38(48.7 \%)$ & 38085 & 0 & 119173 & 0 & 13235 (23.7\%) & 42577 \\
\hline Fengxian District & 63 & $30(47.6 \%)$ & 5830 & 1070 & 31027 & 0 & 4465 (21.1\%) & 16707 \\
\hline Minhang District & 135 & $64(47.4 \%)$ & 48885 & 11575 & 157128 & 0 & 27935 (39.3\%) & 43172 \\
\hline Hungpu District & 29 & $11(37.9 \%)$ & 36245 & 3000 & 144307 & 0 & 15815 (25.2\%) & 46842 \\
\hline Putuo District & 63 & $17(27.0 \%)$ & 12885 & 10385 & 83454 & 52 & $12625(36.5 \%)$ & 21999 \\
\hline Changning District & 44 & $11(25.0 \%)$ & 17485 & 7030 & 77044 & 20 & 7305 (49.2\%) & 7540 \\
\hline Xuhui District & 50 & $7(14.0 \%)$ & 6035 & 1840 & 82538 & 0 & 3470 (86.9\%) & 525 \\
\hline Hongkou District & 41 & 5 (12.2\%) & 11855 & 7830 & 130235 & 0 & $12277(67.1 \%)$ & 6020 \\
\hline
\end{tabular}

Figure 3 System home page (part of the dashboard showing sales statistics of designated pharmacies in 16 districts of Shanghai) used by the government during the COVID19 epidemic in Shanghai.

\section{Practical Effect of the Shanghai Solution}

It has been reported that the Shanghai solution played an important role in ensuring universal wearing of face masks fairly and smoothly. ${ }^{10,11}$ Shanghai started the work of allocation and sales of civilian face masks on February 3, 2020. Distribution on a single day and relationships between cumulative sales and reservation ratios of face masks in each round are depicted in Figures 4 and 5 . We observed that the cumulative sales 


\section{Cumulative Sales Appointment Ratio}

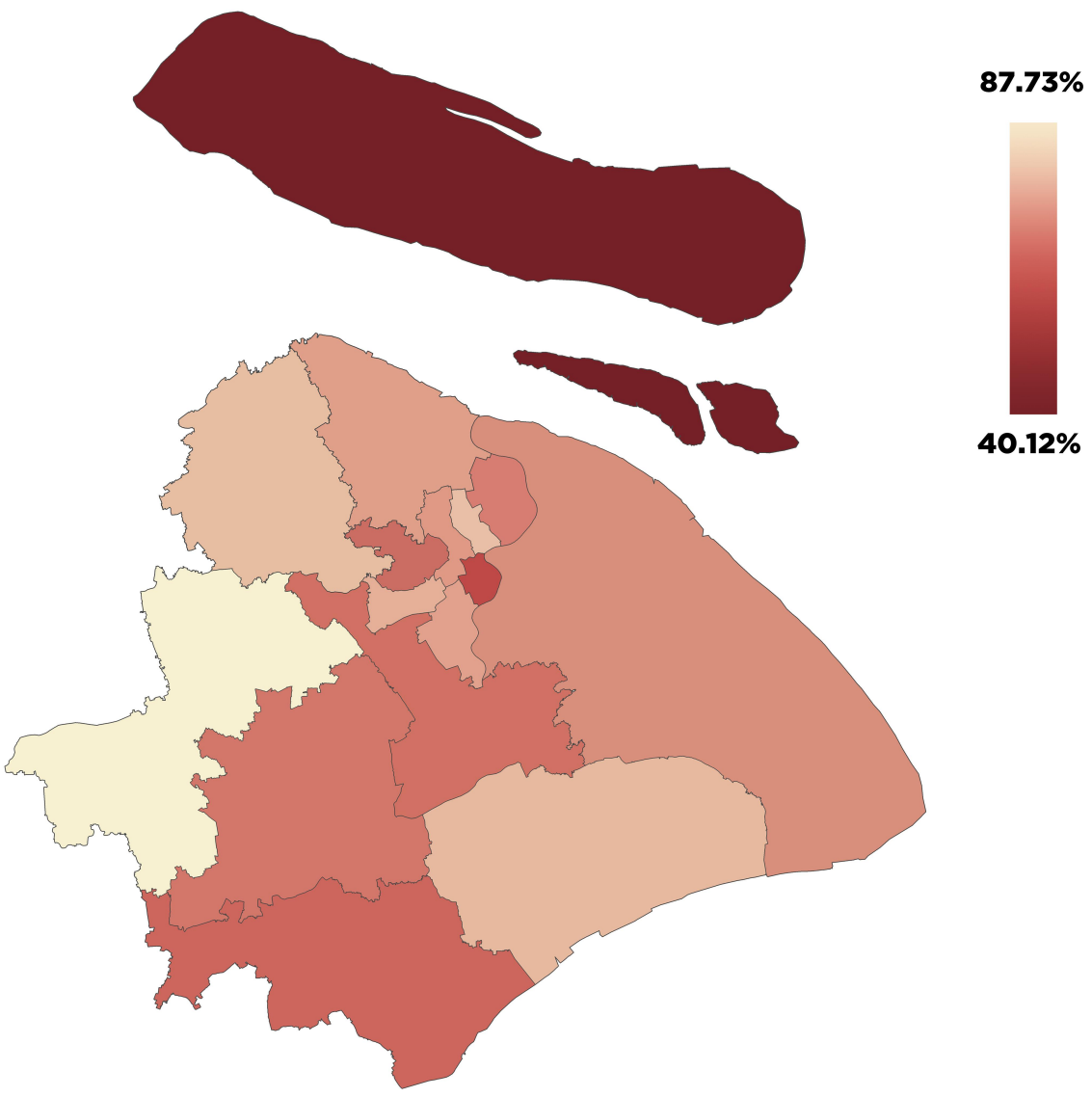

Figure 4 Distribution map of cumulative sales to reservations for face masks on a single day during the COVID-I9 epidemic in Shanghai, as displayed on the system.

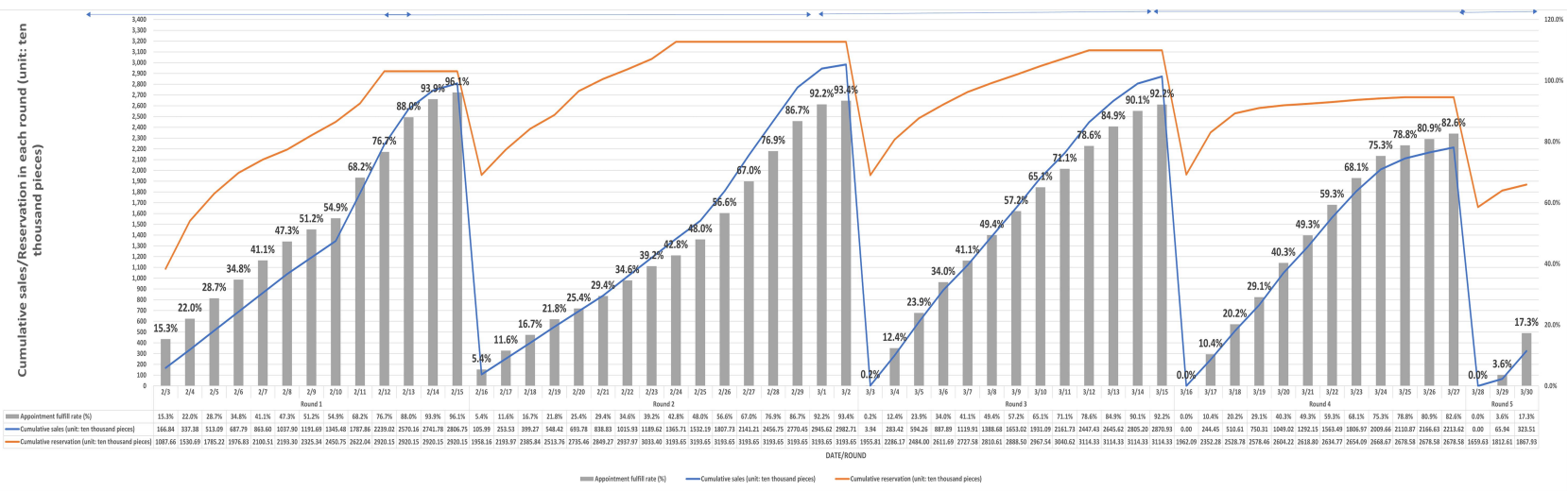

Figure 5 Cumulative civilian face-mask reservations and sales in each round in Shanghai, China.

curve rose gradually and tended to meet the cumulative reservation curve of residents at the late stage of each round. As the number of new infections continued to decline and face mask-productivity in Shanghai improved, the demand of residents for face masks decreased by degrees.
On March 27, 2020, the fourth round was over. Altogether, 108,741 million face masks had been sold in Shanghai and 109,906,200 reservations had been made. The cumulative sales:reservation ratio was $91.33 \%$. The Shanghai solution guaranteed that all citizens in need of face masks were able to receive them in time and the 
phenomenon of queueing to buy face masks avoided. Furthermore, with the support of the university, all data were reviewed through logical calculation to relieve pressure on government staff and reduce data errors. According to the statistics, the data-error rate has been reduced to $<1 \%$ at present, saving at least 1,434 personhours per day.

\section{Discussion}

In this study, we assessed the performance of a citywide universal face mask-wearing strategy in Shanghai during the COVID-19 pandemic. Our study indicated that the Shanghai solution has the following advantages. 1) Ensuring supply to vulnerable populations. A priorityqueuing and -purchasing mechanism was established to those who may lack access to purchasing masks, which was able to protect more citizens from the epidemic. 2) Achieving transparency of face-mask allocation. The online platform displayed information on mask production, distribution, storage, and sales to relevant staff. Timely interference was used to avoid the coexistence of upstream material accumulation and downstream material shortage in the supply chain. 3) Ensuring accessibility for residents. Geographical information and walking distance were taken into consideration when selecting purchase institutions for residents. 4) Combining automation and intelligence calculations to ensure the efficiency and fairness of distribution. Relevant institutions uploaded daily booking, production, sales, and inventory information, and the material-distribution plan would be automatically made based on the calculations in Equations 1-3. 5) Avoidance of crowds. The mechanism of reservation and purchase at different times was established to achieve this.

Previous studies on the allocation of emergency materials have usually focused on solutions to technical problems in the process of distribution. For example, one study developed an emergency material-allocation framework based on time-varying supply-demand constraints to minimize the emergency-response time and satisfy the dynamic emergency-material requirements. ${ }^{12}$ Another study established a workflow system based on a Petri net, in order to improve the dispatch and transportefficiency of emergency materials. ${ }^{13} \mathrm{We}$ aimed to introduce the process of the face mask-allocation strategy in Shanghai in detail, which included information investigation, verification of supply and demand, establishment of a supply-demand database, construction of a queuing mechanism for vulnerable groups, geographical correspondence of supply- demand organizations, determination of distribution volume and cycle, logistical decisions, and statistics of daily production and sales. Description of the entire process makes it possible for other regions or countries to utilize this model for reference and form their own strategies on the dispatch and transportat of emergency materials, such as vaccines, food, daily necessities, and donations.

Apart from Shanghai, other regions and countries have also instituted face mask-distribution policies during the pandemic. Zhejiang and Guangdong provinces used mobile apps to register and make appointments, and then reserved face masks would be delivered to citizens' homes. ${ }^{14,15}$ However, the biggest problem of the strategy adopted by these two provinces was not considering vulnerable groups, which may have caused difficulties in achieving the goal of timely universal wearing of face masks. In addition, mask-distribution policies conducted elsewhere, such as New York, distributed $>100,000$ free masks in parks. ${ }^{16}$ However, this kind of distribution is usually temporary and lacks arrangement, and thus it may cause crowds and unfair distribution. The strategy in Japan was to distribute two cloth masks purchased by the state to each family, and the distribution order depended on the severity of the pandemic. This measure took regional epidemic severity into account, but did not consider differences in availability of masks for different groups of people.

Previous studies on nonsurgical face masks have focused mainly on how to make face masks and people's attitudes toward face mask. ${ }^{17-19}$ Researchers in Kenya proposed a proof of concept of a low-cost and reusable printed 3-D face mask for developing economies. Many countries, such as the US and Japan, have encouraged residents to make cloth face masks and release teaching videos on the $\mathrm{CDC}$ website. These measures ameliorated the problem of insufficient production capacity during the pandemic, although the efficacy of such cloth masks may be limited. Therefore, for those regions or countries with insufficient mask-production capacity, the government could combine these two solutions to ensure the universal wearing of face masks. Using the Shanghai solution would ensure vulnerable groups and citizens had at least some normal masks for going out, and if these were not enough, residents could also make their own masks for emergency usage.

There are several limitations in this study. First, the practical solution focused mainly on proper distribution of face masks to residents, but evaluation of the preventive effects of face masks for residents was not performed. 
Also, we focused on a macroscopic view of the Shanghai solution, so it is almost impossible to explain the technical solutions in each step in detail. As for important technical problems, such as how to use the geographic information system and the personal information database to locate vulnerable groups, or how to use machine learning to establish a queuing mechanism, further studies will be conducted to examine these in detail. Furthermore, information bias might have been inevitable because information collection came from interviews with insiders and work records.

\section{Conclusion}

During the COVID-19 pandemic, the insufficient supply of masks has become a major challenge for all countries. Governments have to find solutions for how to distribute limited masks and achieve the goal of universal wearing of masks for all citizens. Our study introduced a citywide face mask-supply strategy undertaken by the Shanghai Municipal Government during the COVID-19 pandemic, and may provide some suggestions to other countries about how better to manage the preparation, dispatch, and transport of emergency materials in shortage.

\section{Acknowledgments}

This study was supported by the National Natural Science Foundation of China (grant 71874033) and Key Project of Philosophy and Social Science Research of the Ministry of Education (grant 15JZD029).

\section{Author Contributions}

All authors made substantial contributions to conception and design, acquisition of data, or analysis and interpretation of data, took part in drafting the article or revising it critically for important intellectual content, agreed to submit to the current journal, gave final approval to the version to be published, and agree to be accountable for all aspects of the work.

\section{Disclosure}

The authors declare no competing financial interest and report no conflicts of interest for this work.

\section{References}

1. Al-Tawfiq JA, Zumla A, Gautret P, et al. Surveillance for emerging respiratory viruses. Lancet Infect Dis. 2014;14(10):992-1000. doi:10.1016/S1473-3099(14)70840-0

2. Li Z, Gao GF. Infectious disease trends in China since the SARS outbreak. Lancet Infect Dis. 2017;17(11):1113-1115. doi:10.1016/ S1473-3099(17)30579-0

3. Wang C, Horby PW, Hayden FG, Gao GF. A novel coronavirus outbreak of global health concern. Lancet. 2020;395 (10223):470-473. doi:10.1016/S0140-6736(20)30185-9

4. Offeddu V, Yung CF, Low MSF, Tam CC. Effectiveness of masks and respirators against respiratory infections in healthcare workers: a systematic review and meta-analysis. Clin Infect Dis. 2017;65 (11):1934-1942. doi:10.1093/cid/cix681

5. Cn W. Press conference on epidemic prevention and control in Shanghai. 2020. Accessed April 3, 2020.

6. Organization WH. WHO director-general's opening remarks at the media briefing on 2019 novel coronavirus - 7 February 2020. 2020. Accessed February 7, 2020.

7. Applegate WB, Ouslander JG. COVID-19 presents high risk to older persons. J Am Geriatr Soc. 2020;68(4):681. doi:10.1111/jgs. 16426

8. Zhou F, Yu T, Du R, et al. Clinical course and risk factors for mortality of adult inpatients with COVID-19 in Wuhan, China: a retrospective cohort study. Lancet. 2020;395(10229):1054-1062. doi:10.1016/S0140-6736(20)30566-3

9. Zhang TT, Li JM, Bai G, et al. A layout planning methodology of increasing the designated medical insurance drugstores guided by fairness and efficiency. Chin J Health Policy. 2018;11(2):59-63.

10. News XE. Build a mask appointment placement system to ensure that every Shanghai citizen has a mask. 2020. Accessed April 3, 2020.

11. Soho. The second round of mask appointment in Shanghai begins: how Fudan team can realize the quota of masks and accurately launch 1182 pharmacies. 2020. Accessed April 3, 2020.

12. Liu J, Guo L, Jiang J, Jiang D, Wang P. Emergency material allocation with time-varying supply-demand based on dynamic optimization method for river chemical spills. Environ Sci Pollut Res Int. 2018;25(18):17343-17353. doi:10.1007/s11356-018-1489-1

13. Du L. Medical emergency resource allocation model in large-scale emergencies based on artificial intelligence: algorithm development. JMIR Med Inform. 2020;8(6):e19202. doi:10.2196/19202

14. Daily G. Guangdong Province promotes the experience of Guangzhou "online appointment" masks. 2020. Accessed April 3, 2020.

15. Net CN. Appointment of masks for door-to-door delivery in Hangzhou. 2020. Accessed April 4, 2020.

16. CCTV. New York city began to distribute more than 100000 masks to residents free of charge. 2020.

17. Mwema FM, Nyika JM. Challenges in facemasks use and potential solutions: the case study of Kenya. Sci Afr. 2020;10:e00563.

18. Atangana E, Atangana A. Facemasks simple but powerful weapons to protect against COVID-19 spread: can they have sides effects? Results Phys. 2020;19:103425. doi:10.1016/j.rinp.2020.103425

19. Cotrin P, Bahls AC, da Silva DO, et al. The use of facemasks during the COVID-19 pandemic by the Brazilian population. J Multidiscip Healthc. 2020;13:1169-1178. doi:10.2147/JMDH.S281524 


\section{Publish your work in this journal}

Risk Management and Healthcare Policy is an international, peerreviewed, open access journal focusing on all aspects of public health, policy, and preventative measures to promote good health and improve morbidity and mortality in the population. The journal welcomes submitted papers covering original research, basic science, clinical \& epidemiological studies, reviews and evaluations, guidelines, expert opinion and commentary, case reports and extended reports. The manuscript management system is completely online and includes a very quick and fair peer-review system, which is all easy to use. Visit http://www.dovepress.com/testimonials.php to read real quotes from published authors. 